\title{
BALI LEPROSY CAMPAIGN
}

\author{
By Dr. SPEnCER ReEd \\ Government Leprosy Officer, Bali.
}

The leprosy campaign in Bali has been in progress for five years and the year 1961 was the fif th year. The campaign has been based on the use of the sulphones and has shown ever increasing evidence of the value of these drugs. It has been found that in North Bali during the past two years there has been a great increase in the number of patients coming forward voluntarily, but in South Bali fewer patients are now coming forward and there is no real evidence that patients are hiding, so that it may be taken that the campaign has had a very definite effect on the incidence of the disease. In South Bali there has been a good worker who gained the confidence of the people during the last 20 years, resulting in full co-operation from the people. In 1961, a survey was made in South Bali of 97,198 people, which is $74.5 \%$ of the total population at risk, and only 33 additional leprosy patients were found and there was no child case under 15 years of age. This contrasts with the approximate figure of over 200 new patients in North Bali.

For the whole island of Bali the known number of patients in September 1956 was 1,289. By December 1961, 2,016 new cases were added and the total number treated is therefore 3,305. Arrest of the disease was secured in 750 patients.

Treatment of Trophic Ulcers: This matter was taken more actively in 1961. It consisted in a widespread use of applications of gentian violet and brilliant green, and the results were good. There are no funds available for the provision of special shoes.

Deformities: There is an increasing tendency for patients to present themselves before severe deformities. Thus in $195629 \%$ of patients at one centre presented with minor deformities and $28 \%$ with severe deformities, the figures in 1961 were $22 \%$ minor and $2 \%$ severe.

Results of DDS in Bali: It was found to have a genuine effect, and under DDS the progress to healing was troubled by reactions in only $10 \%$. It was found that some degree of hospital treatment was needed for reactions. As regards the duration of the treatment with DDS, it was found that even after 5 years of regular DDS treatment an estimated 5 to $7 \%$ of lepromatous patients remained bacterially positive and this was accompanied by clinical improvement. To secure bacterial inactivity Ciba-1906 and Etisul should be tried, but so far it has not been possible to do this on a sufficient scale.

Drug Resistance to DDS: Over the period of time mentioned in Bali, there has been no evidence of this.

The Effect of DDS in Tuberculoid Leprosy: The eradication of 
leprosy bacilli by DDS in a tuberculoid case is undoubtedly too slow, with consequent danger in nerve reactions and other clinical incidents which lead to ultimate deformity.

Hospital Treatment: There is a treatment ward at Balun Hospital which has proved of great value and there cannot be any organised mass treatment of leprosy without such provision for leprosy patients suffering from recurrent illnesses, leprosy reactions, and surgical conditions such as ulcers and deformities. During 1961 there were 91 such admissions of whom 30 suffered from ulcers and other wounds. As was often found, reactions in some patients were very troublesome and inclined to be continuous.

Notes on other drugs used: Ciba-1906 proved invaluable as an alternative to DDS in reaction cases, both as a new basic drug, and as an accompanying drug once the reactional period seemed to be controlled. It was not so convenient in reacting lepromatous outpatients. Supplies of Ciba-1906 are still insufficient. This also applies to the other drug 'Etisul'. This drug does cause trouble in Bali because of its offensive odour. However, it has proved most useful for certain inpatients. In the latest series of reacting lepromatous patients using Etisul for three months in conjunction with Ciba-1906 and other drugs, at least half have shown marked remission of reaction, and clinically a marked clearing of the skin lesions. The remaining half of the patients showed either intolerance of the drug or had no remission of their reactions.

Desensitization of intolerant cases by the injection of $50 \%$ aqueous solution of Sulphetrone: This remains the accepted method for these cases in Bali, using a slow work up of dosage from $0.1 \mathrm{ml}$. to $1.0 \mathrm{ml}$. over 12 months. The results approached a $100 \%$ successful return of patients to DDS treatment.

Other drugs used for reaction: These were antimony compounds (e.g. Repodrol), chloroquine, sodium bicarbonate and calcium lactate.

The Outpatient Programme: Treatment is now good at over 135 different outpatient centres throughout Bali, mostly at intervals of two weeks. Motor transport and spare parts for the same is at a minimum. Most patients do not have to walk more than 3 to $5 \mathrm{~km}$. Outpatients maintain regularity of attendance at $90 \%$. There still remains a great deal of fear and prejudice, and attention should be given always to this, but it has been found in Bali that an effective leprosy campaign is a good argument with the people against this fear and prejudice, and is also of great value in preventing a recurrence of new cases in the future. A great deal of education and propaganda is still needed as a part of every leprosy campaign, and this is a matter of the number of personnel available. Many leprosy patients are still careless about so living that they are not infectious 
to children. In Bali protective or preventive dosage with DDS is given to such children in selected cases.

\section{Acknowledgment}

The author acknowledges permission to publish to the Director of Medical Services and his co-operation, and that of the Leprosy Institute, Djakarta, and of the Senior Medical Officer, Denpasar, Bali. 